\title{
Pengaruh Kepercayaan Diri dan Harga Diri Terhadap Keterampilan Komunikasi Interpersonal Remaja di Jakarta
}

\author{
Eunike Azalia Pribadi, Rezi Erdiansyah \\ eunike.915160151@stu.untar.ac.ud,rezie@fikom.untar.ac.id \\ Universitas Tarumanagara
}

\begin{abstract}
This research was conducted with the aim to find out whether there is an influence of selfconfidence and self-esteem on adolescent interpersonal communication skills in Jakarta. Researchers took a sample of 150 respondents with criteria: a) adolescents aged between 16 to 21 years, and b) domiciled in the Jakarta area. The results of this study indicate that the level of self-confidence and self-esteem of adolescents in Jakarta affects the interpersonal communication skills of adolescents in Jakarta. Therefore, to improve adolescent interpersonal communication skills in Jakarta, it is necessary to increase the self-confidence and self-esteem of teenagers first.
\end{abstract}

Keywords: interpersonal communication competence, self esteem, self confidence.

\begin{abstract}
Abstrak
Penelitian ini dilaksanakan dengan tujuan untuk mengetahui adakah pengaruh kepercayaan diri (self confidence) dan harga diri (self esteem) terhadap keterampilan komunikasi interpersonal (interpersonal communication) remaja di Jakarta. Peneliti mengambil sampel sebanyak 150 responden dengan kriteria: a) remaja berusia di antara 16 sampai 21 tahun, dan b) berdomisili di wilayah Jakarta. Hasil dari penelitian ini menunjukkan bahwa tingkat kepercayaan diri (self confidence) dan harga diri (self esteem) remaja di Jakarta berpengaruh terhadap keterampilan komunikasi interpersonal (interpersonal communication) remaja di Jakarta. Dengan itu maka untuk meningkatkan keterampilan komunikasi interpersonal (interpersonal communication) remaja di Jakarta, perlu meningkatkan rasa kepercayaan diri (self confidence) dan harga diri (self esteem) para remaja tersebut terlebih dahulu.
\end{abstract}

Kata Kunci: harga diri, kepercayaan diri, keterampilan komunikasi interpersonal

\section{Pendahuluan}

Manusia merupakan makhluk sosial. Sebagai makhluk sosial, tidak bisa hidup sendiri tanpa orang lain. Prabhakara Rao Sampthiaro (2016) mengatakan bahwa kurangnya keterampilan berkomunikasi dapat menyebabkan kemampuan sosial yang rendah dan keberhasilan kerja yang rendah. Setiap orang yang memiliki kecemasan komunikasi yang rendah melakukan komunikasi interpersonal untuk kesenangan, kasih sayang, kontrol, dan relaksasi, sedangkan setiap orang yang memiliki kecemasan komunikasi yang tinggi akan melakukan komunikasi interpersonal untuk inklusi dan melarikan diri.

Selanjutnya Rebecca B. Rubin \& Matthew M. Martin (1994) mengatakan komunikasi interpersonal merupakan sebuah konstruk yang beragam dan dikatakan bahwa mengajarkan keterampilan komunikasi interpersonal di kelas komunikasi sangatlah penting. Menurut tokoh di atas, maka dapat disimpulkan bahwa keterampilan seseorang dalam melakukan komunikasi interpersonal sangatlah penting karena komunikasi interpersonal menentukan kemampuan sosial seseorang serta 
respon dan tujuan seseorang saat melakukan komunikasi interpersonal. Keterampilan komunikasi interpersonal seseorang dapat dikaitkan dengan rasa kepercayaan diri dan harga diri seseorang tersebut.

Menurut Dian Oktary, Marjohan, dan Syahniar (2019) keterampilan komunikasi interpersonal dipengaruhi oleh kepercayaan diri dan support sosial dari orang tua. Selanjutnya dikatakan oleh Siska, Sudarjo, dan Esti Hayu Purnamaningsih (2003) kepercayaan diri berpengaruh terhadap kecemasan komunikasi interpersonal pada mahasiswa. Dan menurut pendapat dari Prabhakara Rao Sampthiaro (2016) bagaimana kita berkomunikasi dipengaruhi dari konsep diri kita khususnya harga diri. Edric Kusuma dan Sunarto (2017) mengatakan komunikasi interpersonal yang baik meningkatkan kualitas diri seseorang dalam pekerjaannya.

Kepercayaan diri adalah sikap dimana seseorang yakin atas kemampuan diri sendiri sehingga merasa sopan dalam berinteraksi dengan orang lain dan tidak cemas dalam mengambil tindakan apapun. (Lauster, dalam Linda Lestari, Muswardi Rosra, dan Shinta Mayasari, 2019). Selain kepercayaan diri, faktor harga diri dipandang sebagai suatu aspek yang penting dalam proses terbentuknya kepribadian seseorang, terlihat bahwa harga diri yang tinggi membentuk pribadi yang positif dan sikap baik saat berinteraksi dengan orang lain (Wilis Srisayekti, David A. Setiady, dan Rasyid Bo Sanitioso, 2015). Dari pendapat tokoh diatas maka dapat disimpulkan bahwa rasa kepercayaan diri dan harga diri menentukan bagaimana seseorang berinteraksi dengan orang lain.

Syamsul Bachri Thalib (1999) mengatakan bahwa seseorang yang memandang dirinya positif memiliki keyakinan bahwa ia akan diterima oleh orang lain dan memiliki kemungkinan yang lebih besar untuk dapat mengembangkan pergaulan dan juga hubungan interpersonal. Selanjutnya Rahmah Putri Puspitasari dan Hermien Laksmiwati, (2012), mengatakan bahwa hubungan interpersonal tidak bersifat statis, melainkan dapat berubah. Untuk menjaga hubungan interpersonal agar tetap baik, ada 4 faktor penting yaitu, kontrol, keakraban, nada emosional yang tepat, dan respon yang tepat.

Penelitian ini akan mengkaji pengaruh dari kepercayaan diri (self confidence) dan harga diri (self esteem) terhadap keterampilan komunikasi interpersonal remaja. Pemilihan remaja sebagai subjek penelitian ini, dengan alasan karena ada banyak halhal yang sangat berkaitan erat antara komunikasi interpersonal (interpersonal communication) yang sangat berkaitan dengan kehidupan remaja (Chrispin Thurlow, 2003). Masa remaja merupakan segmen yang penting di dalam siklus perkembangan kehidupan seseorang, dan juga masa transisi yang dapat juga diarahkan perkembangan yang sehat dan dewasa di masa depan (Khamim Zarkasih Putro, 2017). Menurut kedua tokoh tersebut maka dapat disimpulkan bahwa remaja merupakan sosok yang sedang mengalami pertumbuhan sehingga belum stabil. Dikatakan bahwa pola interaksi remaja yang seringkali berubah-ubah menandakan bahwa remaja merupakan sosok yang masih labil dan juga masa remaja merupakan masa dimana seseorang mencari jati dirinya dan apa yang ia alami selama masa remajanya menentukan bagaimana ia di saat sudah dewasa. Hal ini membuat remaja menjadi subjek yang menarik untuk diteliti berkaitan dengan rasa percaya diri dan harga diri terhadap keterampilan dalam melakukan komunikasi interpersonal.

Penelitian ini dilakukan di kota Jakarta. Peneliti memilih Jakarta sebagai tempat untuk melakukan penelitian karena Jakarta merupakan ibukota yang ramai penduduk. Banyak keluarga yang memiliki latar belakang beragam di kota ini, sehingga remajanya juga memiliki karakter yang beragam. Banyak sekali remaja di 
Eunike Azalia Pribadi, Rezi Erdiansyah: Pengaruh Kepercayaan Diri dan Harga Diri Terhadap Keterampilan Komunikasi Interpersonal Remaja di Jakarta

Jakarta yang memiliki latar belakang kurang baik sehingga mempengaruhi rasa percaya diri dan harga diri di pergaulan.

\section{Metode Penelitian}

Peneliti menggunakan pendekatan kuantitatif dalam menganalisis data penelitian. Definisi penelitian kuantitatif merupakan penelitian yang menggunakan desain eksplanasi dimana objek yang ditelaah penelitian eksplanasi yaitu untuk menguji hubungan yang dihipotesiskan dari antar-variabel (Muhammad Mulyadi, 2003).

Metode penelitian yang digunakan dalam penelitian ini adalah survey. Metode penelitian survey adalah metode penelitian mengenai objek-objek tertentu, dan objek tersebut membutuhkan informasi yang banyak sehingga diperlukan alat yang berguna untuk mewadahi setiap data yang menggunakan daftar isian atau juga daftar pertanyaan (Risma Fadhilla Arsy, 2013).

Penelitian ini menggunakan metode pengumpulan data berupa angket atau kuesioner. Angket atau kuesioner adalah sebuah set pertanyaan yang secara logis berhubungan dengan masalah yang sedang diteliti, dan setiap pertanyaan yang diberikan merupakan jawaban-jawaban yang memiliki makna untuk menguji hipotesis (Moh. Nazir, Ph.D, 2011). Dalam penelitian ini penelitian dilaksanakan dengan menyebarkan kuesioner kepada remaja yang menjadi populasi di dalam penelitian. Populasi yang diambil dalam penelitian ini adalah remaja berusia 16-21 tahun yang berdomisili di Jakarta. Jumlah responden yang diambil di dalam penelitian ini berdasarkan banyaknya indikator pada penelitian lalu dikali dengan 5 (Hair et al dalam Dwi Aryani dan Febrina Rosinta, 2010). Indikator di dalam penelitian ini berjumlah sebanyak 28 indikator. Jadi perhitungannya adalah $28 \times 5$, yaitu sebanyak 140 responden. Menurut Sudjana (2000, dalam Jefri Heridiansyah, 2012) populasi merupakan kumpulan secara lengkap dari semua elemen sejenis dan dibedakan menjadi objek penelitian. Kuesioner/angket dalam penelitian ini menggunakan skala likert. Skala likert merupakan skala yang menggunakan item yang sudah pasti baik atau yang sudah pasti buruk, sehingga dapat diketahui seberapa kuat tingkat setuju dan tidak setuju dari subyek (Moh. Nazir, Ph.D, 2011). Menurut Malhotra (2004, dalam Happy Fransisca \& Drs. Sugiyono, M.M., 2014) skala likert merupakan pengukuran skala yang menggunakan 5 (lima) kategori, yaitu Sangat Tidak Setuju (STS), Tidak Setuju (TS), Netral (N), Setuju (S), dan Sangat Setuju (SS).

(Ir. Syofian Siregar, M.M. 2013) Ada beberapa pengolahan yang digunakan dalam penelitian, yang pertama adalah editing. Editing merupakan suatu proses pemeriksaan suatu data yang telah berhasil disimpulkan dari lapangan, karena adanya kemungkinan bahwa data yang masuk tidak memenuhi syarat yang ditentukan. Kemudian yang kedua adalah codeting. Codeting merupakan kegiatan memberi kode tertentu pada setiap data yang yang termasuk ke dalam satu kategori. Kode merupakan isyarat yang dibuat berbentuk angka atau huruf untuk dapat membedakan antara data atau identitas dari data yang akan dianalisis. Dan yang ketiga adalah tabulasi. Tabulasi merupakan proses penempatan suatu data ke dalam tabel yang sudah diberi kode sesuai dengan kebutuhan analisis.

Dalam penelitian ini teknik pengolahan data menggunakan dua perangkat lunak (software) pengolah data yaitu program statistical product and service solutions (SPSS) untuk menguji keabsahan data yaitu validitas dan realibitas dan program structural equation model (SEM) untuk melakukan pengujian hipotesis. Structural 
Equation Modeling (SEM) adalah teknik analisis multivariat yang dikembangkan dengan guna untuk menutupi suatu keterbatasan yang dimiliki oleh model analisis sebelumnya dan yang telah dipakai secara luas di dalam penelitian statistika (Enggar Nur Sasongko, Mustafid, dan Agus Rusgiyono, 2016).

\section{Hasil Temuan dan Diskusi}

Uji validitas menunjukkan sudah sejauh manakah suatu perbedaan dalam skor yang terdapat pada suatu instrumen yang mencerminkan kebenaran dari suatu perbedaan yang ada di antara individu, kelompok, atau situasi dalam suatu karakteristik yang ditemukan bagi ukuran (Dr. Ulber Silalahi, M.A., 2017).

Menurut Azwar (1992, dalam Ir. Syofian Siregar, M.M., 2012: 47) dan Soegiyono (1999, dalam Ir. Syofian Siregar, M.M., 2012) kriteria yang dapat digunakan agar dapat mengetahui apakah kuesioner tersebut sudah benar atau belum benar untuk mengukur apa yang akan diukur, yaitu:

1. Bila koefisien korelasi product moment dapat lebih dari 0,3 maka kuesioner yang digunakan bisa dikatakan sudah tepat.

2. Bila koefisien korelasi product moment $>\mathrm{r}-(\alpha ; \mathrm{n}-2) \mathrm{n}=$ jumlah sampel

3. Bila Nilai sig $\leq \alpha$

Menurut Nisfiannoor (2009: 229-230) untuk menilai apakah butir dalam kuesioner valid atau tidak yaitu apabila nilai corrected item total correlation seluruhnya diatas 0.2 , maka setiap item pertanyaan terbukti valid.

Tabel 1. Hasil Uji Validitas

\begin{tabular}{|c|c|c|c|}
\hline Variabel & Butir Indikator & $\begin{array}{l}\text { Corrected } \\
\text { Item Total } \\
\text { Correlation }\end{array}$ & Keterangan \\
\hline \multirow[t]{9}{*}{$\begin{array}{l}\text { Kepercayaan Diri } \\
\text { (Self Confidence) }\end{array}$} & $\begin{array}{l}\text { Saya merasa yakin dengan } \\
\text { kemampuan yang saya miliki }\end{array}$ & 0.450 & Valid \\
\hline & $\begin{array}{l}\text { Saya mampu menghadapi setiap } \\
\text { masalah yang menimpa saya }\end{array}$ & 0.647 & Valid \\
\hline & $\begin{array}{l}\text { Saya yakin dengan setiap keputusan } \\
\text { yang saya ambil }\end{array}$ & 0.617 & Valid \\
\hline & $\begin{array}{l}\text { Saya memandang segala sesuatu } \\
\text { yang terjadi dengan positif }\end{array}$ & 0.538 & Valid \\
\hline & $\begin{array}{l}\text { Saya selalu menjalankan setiap } \\
\text { tugas yang diberikan dengan sebaik } \\
\text { mungkin }\end{array}$ & 0.437 & Valid \\
\hline & $\begin{array}{l}\text { Saya dapat } \\
\text { mempertanggungjawabkan setiap } \\
\text { keputusan yang saya pilih }\end{array}$ & 0.652 & Valid \\
\hline & $\begin{array}{l}\text { Saya selalu memandang setiap } \\
\text { masalah yang menimpa saya dengan } \\
\text { pikiran terbuka }\end{array}$ & 0.603 & Valid \\
\hline & $\begin{array}{l}\text { Saya dapat memberi penilaian } \\
\text { terhadap sekitar dengan adil dan } \\
\text { objektif }\end{array}$ & 0.490 & Valid \\
\hline & $\begin{array}{l}\text { Saya lebih mengedepankan akal } \\
\text { sehat dibandingkan dengan perasaan }\end{array}$ & 0.469 & Valid \\
\hline
\end{tabular}


Eunike Azalia Pribadi, Rezi Erdiansyah: Pengaruh Kepercayaan Diri dan Harga Diri Terhadap Keterampilan Komunikasi Interpersonal Remaja di Jakarta

\begin{tabular}{|c|c|c|c|}
\hline & $\begin{array}{l}\text { Setiap masalah yang terjadi dapat } \\
\text { saya selesaikan dengan pikiran yang } \\
\text { logis/rasional }\end{array}$ & 0.486 & Valid \\
\hline \multirow{8}{*}{$\begin{array}{l}\text { Harga Diri }(\text { Self } \\
\text { Esteem) }\end{array}$} & Saya merasa diri saya berharga & 0.320 & Valid \\
\hline & $\begin{array}{l}\text { Saya memiliki perasaan aman } \\
\text { terhadap diri saya sendiri }\end{array}$ & 0.478 & Valid \\
\hline & $\begin{array}{l}\text { Saya dapat mengendalikan diri } \\
\text { dengan baik }\end{array}$ & 0.605 & Valid \\
\hline & $\begin{array}{l}\text { Saya dapat mengontrol dan } \\
\text { mengendalikan orang di sekitar saya } \\
\text { agar mereka dapat mengikuti apa } \\
\text { yang saya katakan dan lakukan }\end{array}$ & 0.591 & Valid \\
\hline & $\begin{array}{l}\text { Saya mampu melakukan banyak hal } \\
\text { dalam kegiatan saya }\end{array}$ & 0.617 & Valid \\
\hline & $\begin{array}{l}\text { Setiap tugas yang saya kerjakan } \\
\text { selalu memperoleh hasil yang } \\
\text { sangat baik }\end{array}$ & 0.588 & Valid \\
\hline & $\begin{array}{l}\text { Saya menyelesaikan setiap masalah } \\
\text { dengan cara yang bijak dan tepat }\end{array}$ & 0.527 & Valid \\
\hline & $\begin{array}{l}\text { Saya selalu menyusun strategi } \\
\text { sebaik mungkin agar setiap tujuan } \\
\text { yang saya inginkan tercapai }\end{array}$ & 0.373 & Valid \\
\hline \multirow{10}{*}{$\begin{array}{c}\text { Komunikasi } \\
\text { Interpersonal } \\
\text { (Interpersonal } \\
\text { Communication) }\end{array}$} & $\begin{array}{l}\text { Saya seringkali turut merasakan apa } \\
\text { yang dirasakan oleh orang lain }\end{array}$ & 0.413 & Valid \\
\hline & $\begin{array}{l}\text { Saya sering memberi respon } \\
\text { terhadap apa yang dialami dan } \\
\text { dirasakan oleh orang lain }\end{array}$ & 0.531 & Valid \\
\hline & $\begin{array}{l}\text { Saya selalu jujur saat berkomunikasi } \\
\text { dengan orang lain }\end{array}$ & 0.462 & Valid \\
\hline & $\begin{array}{l}\text { Saya merasa nyaman untuk } \\
\text { mengeluarkan pendapat saya tanpa } \\
\text { adanya rasa takut terintimidasi }\end{array}$ & 0.442 & Valid \\
\hline & $\begin{array}{l}\text { Saya seringkali memberi semangat } \\
\text { kepada orang di sekitar saya }\end{array}$ & 0.508 & Valid \\
\hline & $\begin{array}{l}\text { Saya selalu memberi respon positif } \\
\text { terhadap orang lain }\end{array}$ & 0.587 & Valid \\
\hline & $\begin{array}{l}\text { Saya merasa setara dengan orang } \\
\text { lain yang sedang melakukan } \\
\text { komunikasi interpersonal dengan } \\
\text { saya }\end{array}$ & 0.614 & Valid \\
\hline & $\begin{array}{l}\text { Saya memandang konflik yang } \\
\text { terjadi saat saya melakukan } \\
\text { komunikasi interpersonal sebagai } \\
\text { upaya untuk menerima perbedaan } \\
\text { yang ada }\end{array}$ & 0.477 & Valid \\
\hline & $\begin{array}{l}\text { Saya selalu menghargai orang lain } \\
\text { yang sedang berkomunikasi dengan } \\
\text { saya }\end{array}$ & 0.519 & Valid \\
\hline & $\begin{array}{l}\text { Saya memandang orang lain yang } \\
\text { sedang berkomunikasi dengan saya } \\
\text { sama berharganya dengan diri saya } \\
\text { sendiri }\end{array}$ & 0.319 & Valid \\
\hline
\end{tabular}

Sumber: Data primer, diolah dengan SPSS 23 
Dari tabel uji validitas diatas maka disimpulkan bahwa setiap pertanyaan yang berasal dari seluruh variabel penelitian ini dapat dikatakan valid karena angka korelasi lebih besar dari 0.2 .

Selanjutnya uji yang dilakukan adalah uji reliabilitas, reliabilitas menekankan pertanyaan apakah responden memberi jawaban secara konsisten atau stabil. Suatu instrumen dapat dikatakan reliabel apabila pengukuran dilaksanakan secara berulang kali terhadap suatu konsep dan menghasilkan suatu nilai yang tidak berubah (Dr. Ulber Silalahi, M.A., 2017: 462). Instrumen penelitian dapat dikatakan reliabel dengan teknik ini apabila koefisien reliabilitas $>0.6$.

Tabel 2. Hasil Uji Reliabilitas

\begin{tabular}{ccc}
\hline Variabel & Cronbach's Alpha & Keterangan \\
\hline $\begin{array}{c}\text { Kepercayaan Diri (Self } \\
\text { Confidence) }\end{array}$ & 0.840 & Reliable \\
\hline Harga Diri (Self Esteem) & 0.801 & Reliable \\
\hline $\begin{array}{c}\text { Komunikasi Interpersonal } \\
\text { (Interpersonal Communication) }\end{array}$ & 0.807 & Reliable \\
\hline
\end{tabular}

Sumber: Data primer, diolah dengan SPSS 23

Berdasarkan tabel 2 dapat dilihat bahwa hasil uji reliabilitas dari variabel kepercayaan diri, harga diri, dan komunikasi interpersonal remaja di Jakarta dapat dikatakan bahwa semua variabel tersebut reliabel karena memiliki angka di atas 0.6. Dapat terlihat dari variabel kepercayaan diri memiliki nilai Cronbach Alpha sejumlah 0.840, variabel harga diri memiliki nilai Cronbach Alpha sejumlah 0.801, dan variabel komunikasi interpersonal memiliki nilai Cronbach Alpha sejumlah 0.807.

Tabel 3. Tabel Hasil Pengujian Hipotesis

\begin{tabular}{|c|c|c|c|c|c|}
\hline Hypothesis & Path & $\begin{array}{l}\text { Standardized } \\
\text { Solution }\end{array}$ & T-Values & T-Table & Results \\
\hline H1 & $\begin{array}{c}\text { Kepercayaan Diri } \\
\text { (Self Confidence) } \\
\text { (X1) } \\
\downarrow \\
\text { Komunikasi } \\
\text { Interpersonal } \\
\text { (Interpersonal } \\
\text { Communication) } \\
\text { (Y) }\end{array}$ & 0.34 & 1.96 & 1.96 & Supported \\
\hline $\mathrm{H} 2$ & $\begin{array}{c}\text { Harga Diri (Self } \\
\text { Esteem) (X2) } \\
\text { Komunikasi } \\
\text { Interpersonal } \\
\text { (Interpersonal } \\
\text { Communication) } \\
\text { (Y) }\end{array}$ & 0.54 & 2.33 & 1.96 & Supported \\
\hline
\end{tabular}




\begin{tabular}{ccccc}
\hline H3 & Kepercayaan & & & Supported \\
Diri (Self & & & & \\
Confidence) & 0.71 & 2.44 & 1.96 & \\
(X1) dan Harga & & & & \\
Diri (Self & & & \\
Esteem) (X2) & & & \\
& $\downarrow$ \\
Komunikasi & & \\
Interpersonal \\
(Interpersonal \\
Communication) \\
(Y)
\end{tabular}

Sumber: Data diolah dengan LISREL SEM 8.80.

Pada hipotesis H1 nilai T-Value adalah 1.96, dengan nilai Standardized Solution yaitu 0.34 . Karena nilai dari $T$-value $>$ dari nilai T-tabel, $T$-value $=4.32>\mathrm{T}$ tabel $=1.96$, maka $\mathrm{H} 0$ tidak dapat diterima dan $\mathrm{H} 1$ dapat diterima, yang berarti terdapat pengaruh yang signifikan antara kepercayaan diri terhadap komunikasi interpersonal. Dengan demikian semakin tinggi tingkat kepercayaan diri seseorang maka keterampilan komunikasi interpersonalnya lebih baik, sebaliknya semakin rendah tingkat kepercayaan diri seseorang maka keterampilan komunikasi interpersonalnya akan kurang baik. Sama halnya dengan penelitian terdahulu dari Dika Saputra, Syahniar, dan Marjohan (2016) dengan judul "Kontribusi Kepercayaan Diri dan Kecerdasan Emosi terhadap Komunikasi Interpersonal Siswa serta Implikasinya dalam Pelayanan Bimbingan Konseling" dikatakan bahwa kepercayaan diri berkontribusi secara signifikan terhadap komunikasi interpersonal.

Pada hipotesis H2 nilai T-value adalah 2.88, dan nilai Standardized Solution yaitu 0.54. Karena nilai $T$-value $>$ dari nilai T-tabel, $T$-value $=2.88>\mathrm{T}$-tabel $=1.96$, maka $\mathrm{H} 0$ tidak dapat diterima dan $\mathrm{H} 2$ dapat diterima, yang berarti terdapat pengaruh yang signifikan antara harga diri terhadap komunikasi interpersonal. Dengan begitu semakin tinggi rasa harga diri seseorang maka tingkat keterampilan komunikasi interpersonalnya juga lebih baik, sebaliknya semakin rendah rasa harga diri seseorang, maka tingkat keterampilan komunikasi interpersonalnya akan kurang baik. Sama halnya penelitian terdahulu dari Prabhakara Rao Sampthiaro (2016) dengan judul "Self-Concept and Interpersonal Communication" dikatakan bahwa rasa harga diri seseorang mempengaruhi kemampuan bergaul, bersikap, dan berkomunikasi dengan orang lain.

Pada hipotesis H3 nilai T-Value adalah 2.44, dan nilai Standardized Solution adalah 0.71. Karena nilai $T$-Value $>$ dari nilai T-Tabel, $T$-Value $=2.44>$ T-tabel $=1.96$ maka H0 tidak dapat diterima dan H3 dapat diterima, yang berarti kepercayaan diri dan harga diri memiliki pengaruh yang signifikan terhadap komunikasi interpersonal. Dengan begitu semakin tinggi tingkat kepercayaan diri dan harga diri seseorang maka keterampilan komunikasi interpersonalnya lebih baik, sebaliknya semakin rendah tingkat kepercayaan diri dan harga diri seseorang maka keterampilan komunikasi interpersonalnya akan kurang baik. 


\section{Simpulan}

Berdasarkan hasil dari penelitian dan pembahasan dalam beberapa bab sebelumnya tentang pengaruh kepercayaan diri dan harga diri terhadap keterampilan komunikasi interpersonal remaja di Jakarta, ada beberapa hal yang disimpulkan peneliti, yaitu:

1. Kepercayaan Diri (Self Confidence) berpengaruh signifikan terhadap keterampilan Komunikasi Interpersonal (Interpersonal Communication).

2. Harga Diri (Self Esteem) berpengaruh signifikan terhadap keterampilan Komunikasi Interpersonal (Interpersonal Communication).

3. Kepercayaan Diri (Self Confidence) dan Harga Diri (Self Esteem) berpengaruh signifikan terhadap keterampilan Komunikasi Interpersonal (Interpersonal Communication).

4. Variabel yang berkontribusi paling besar terhadap komunikasi interpersonal (interpersonal communication) adalah variabel harga diri (self esteem) dengan nilai T-value sebesar 2.33. Dengan demikian keterampilan komunikasi interpersonal (interpersonal communication) begitu dipengaruhi oleh tingkat harga diri (self esteem).

5. Hipotesis yang paling dominan dalam penelitian adalah hipotesis $3(\mathrm{H} 3)$ yaitu kepercayaan diri (self confidence) dan harga diri (self esteem) berpengaruh signifikan terhadap keterampilan komunikasi interpersonal (interpersonal communication) remaja di Jakarta dengan nilai T-value sebesar 2.44 dan Standardized Solution sebesar 0.71.

\section{Ucapan Terima Kasih}

Puji dan syukur kepada Tuhan YME atas segala berkat dan rahmat-Nya sehingga peneliti dapat melaksanakan kegiatan penelitian dan menyelesaikan penulisan laporan akhir skripsi ini. Peneliti mengharapkan bahwa skripsi ini dapat menambah wawasan pihak lain. Di akhir kata penulis mengucapkan sekian dan terima kasih.

\section{Daftar Pustaka}

Arsy, Risma Fadhilla. (2013). Metode Survei Deskriptif Untuk Mengkaji Kemampuan Interpretasi Citra Pada Mahasiswa Pendidikan Geografi FKIP Universitas Tadulako. Jurnal Ilmu Geografi, 62-72.

Aryani, Dwi., Rosinta, Febrina. (2010). Pengaruh Kualitas Layanan terhadap Kepuasan Pelanggan dalam Membentuk Loyalitas Pelanggan. Jurnal Ilmu Administrasi dan Organisasi, 17, 114-126.

Fitri, Emia., Zola, Nilma., Ifdil, Ifdil. (2018). Profil Kepercayaan Diri Remaja serta Faktor-Faktor yang Mempengaruhi. JPPI (Jurnal Penelitian Pendidikan Indonesia), 4, 1-5.

Fransisca, Happy., Sugiyono. (2014). Perspektif Konsumen Terhadap Retail Mix di Ayam Bakar Primarasa Ahmad Yani Surabaya. Jurnal Manajemen Pemasaran Petra, 2, 1-9.

Heridiansyah, Jefri. (2012). Pengaruh Advertising Terhadap Pembentukan Brand Awareness Serta Dampaknya Pada Keputusan Pembelian Produk Kecap Pedas ABC. Jurnal STIE Semarang, 4, 53-73. 
Eunike Azalia Pribadi, Rezi Erdiansyah: Pengaruh Kepercayaan Diri dan Harga Diri Terhadap

Kusuma, Edric., Sunarto. (2017). Strategi Komunikasi Antar Pribadi Dalam Rangka Meningkatkan Kinerja di PT Granton Marketing. Jurnal Komunikasi Universitas Tarumanagara. 1.

Lestari, Linda., Rosra, Muswardi., Nayasari, Shinta. (2019). Hubungan Kepercayaan Diri Dengan Komunikasi Interpersonal Siswa SMP. 7.

Mulyadi, Mohammad. (2003). Penelitian Kuantitatif dan Kualitatif serta Pemikiran Dasar Menggabungkannya. Jurnal Studi Komunikasi dan Media, 15, 127-138.

Nazir, Moh. (2011). METODE PENELITIAN. Bogor: Penerbit Ghalia Indonesia.

Nisfiannoor, Muhammad. (2009). Pendekatan Statistika Modern. Jakarta: Salemba Huamanika.

Oktary, Dian., Marjohan., Syahniar. (2019). The Effects of Self-Confidence and Social Support of Parents on Interpersonal Communication of Students. Journal of Educational and Learning Studies, 2, 5-11.

Pujihastuti, Isti. (2010). PRINSIP PENULISAN KUESIONER PENELITIAN. Jurnal Agribisnis dan Pengembangan Wilayah, 2, 43-56.

Puspitasari, Rahmah Putri., Laksmiwati, Hermien. (2012). HUBUNGAN KONSEP DIRI DAN KEPERCAYAAN DIRI DENGAN KEMAMPUAN KOMUNIKASI INTERPERSONAL PADA REMAJA PUTUS SEKOLAH. Jurnal Psikologi: Teori \& Terapan, 3, 58-66.

Putro, Khamim Zarkasih. (2017). Memahami Ciri dan Tugas Perkembangan Masa Remaja. APLIKASIA: Jurnal Aplikasi Ilmu-ilmu Agama, 17, 25-32.

Rahman, Ali. (2016). BENTUK-BENTUK KOMUNIKASI DALAM PEMBELAJARAN. Paedagogia: Jurnal Pendidikan, 5, 198-217.

Rubin, Rebecca B., Martin, Matthew M. (1994). Development of a Measure of Interpersonal Communication Competence. Communication Research Report, 11, 33-44.

Sahputra, Dika., Syahniar., Marjohan. (2018). Kontribusi Kepercayaan Diri dan Kecerdasan Emosi terhadap Komunikasi Interpersonal Siswa serta Implikasinya dalam Pelayanan Bimbingan dan Konseling. Konselor, 5, 182193.

Sampthirao, Prabhakararao. (2016). Self-Concept and Interpersonal Communication. The International Journal of Indian Psychology, 3, 177-189.

Sasongko, Enggar Nur., Mustafid., Rusgiyono, Agus. (2016). PENERAPAN METODE STRUCTURAL EQUATION MODELING UNTUK ANALISIS KEPUASAN PENGGUNA SISTEM INFORMASI AKADEMIK TERHADAP KUALITAS WEBSITE. Jurnal Gaussian, 5, 395-404.

Silalahi, Ulber. (2017). METODE PENELITIAN SOSIAL KUANTITATIF. Bandung: Refika Aditama.

Siregar, Syofian. (2017). Metode Penelitian Kuantitatif. Jakarta: PT. Fajar Interpratama Mandiri.

Srisayekti, Wilis., Setiady, David A., Sanitioso, Rasyid Bo. (2015). Harga-diri (Selfesteem) Terancam dan Perilaku Menghindar. Jurnal Psikologi, 42, 141-156.

Sudarjo, Siska., Purnamaningsih, Esti Hayu. (2003). KEPERCAYAAN DIRI DAN KECEMASAN KOMUNIKASI INTERPERSONAL PADA MAHASISWA. Jurnal Psikologi, 2, 67-71.

Thalib, Syamsul Bachri. (1999). Hubungan Percaya Diri dan Harga Diri dengan Kemampuan Bergaul Mahasiswa. Jurnal Ilmu Pendidikan, 6, 247-256. 
Vol. 3, No. 2, Desember 2019, Hal 453-462

Thurlow, Chrispin. (2003). TEENAGERS IN COMMUNICATION, TEENAGERS ON COMMUNICATION. Journal of Language and Social Psychology, 22, $50-57$. 